\title{
Establishing and maintaining international collaborative research teams: an autobiographical insight
}

\author{
TJ CARR, ${ }^{1}$ C VAN DER WALT, ${ }^{2}$ F WATSON ${ }^{3}$ AND N LINDA ${ }^{4}$
}

\begin{abstract}
Despite the growing impetus for international collaborative research teams (ICRT), there are relatively few resources available to guide and support researchers through the processes of establishing and maintaining ICRTs. In particular, no articles were found that provided researchers' firsthand accounts of being a member of such a team. Having access to such personal accounts can help both experienced and novice researchers learn more directly about what to expect, as well as the benefits, challenges, pitfalls, and success strategies for establishing and maintaining ICRTs. The authors used phenomenological autobiographical reflective journaling to capture their experiences as members of ICRTs. In this article we provide an overview of key themes that emerged from the analysis of our reflections as members of ICRTs. These themes include: benefits, challenges, and strategies for success. Our aim is to share our first-hand experiences of what it is like to establish and participate in ICRT. It is not our intention to provide readers with prescriptive guidelines on how to set up and maintain ICRTs. Every ICRT is unique and some of these ideas may or may not apply in every case. Instead, we are describing what worked for us, hoping that others may benefit from our experience. Consequently, we suggest that the focus of ICRT should be on the benefits thereof which promote and encourage interaction between disciplines, transfer of knowledge and techniques and personal and professional development.
\end{abstract}

Keywords: international, collaborative, research, teams, interdisciplinary

An international collaborative research team (ICRT) can be described as an alliance between researchers from different countries and institutions who share a common goal and the responsibility for achieving it. Such collaboration can be described as symmetrical, suggesting that scientists from participating countries participate in a relatively equivalent manner (Kim, 2006). Within such a team, information and other resources can be exchanged and collaborative research projects planned, implemented, and disseminated (Boonekamp, Costongs, Logghe, \& vander Veene, 2000). According to Abell \& Rultedge (2009), ICRTs share not only resources, but also risks, power, and authority. They likewise point out that

1. Department of Nursing and Health Sciences, University of New Brunswick Saint John, P.O. Box 5050, Saint John, NB, E2L 4L5, E-mail: tcarr@unbsj.ca, Phone: 506-648-5664, Fax: 506-648-5784.

2. North-West University, South Africa.

3. North-West University, South Africa.

4. University of the Western Cape, South Africa.

TD The Journal for Transdisciplinary Research in Southern Africa, 9(1) July 2013, pp. 94 - 112. 
effective ICRTs are based on mutual knowledge and common ground, which can be a challenge to achieve across different time zones, nationalities, and cultures (Abell \& Rutledge, 2009).

In the light of the above mentioned advantages, the establishment of global linkages and collaborative relationships among health researchers, decision makers, and practitioners is becoming increasingly common (Bossert, Evans, Van Cleve, \& Savedra, 2002). Establishing ICRTs is a top priority for major international health care organizations and health research funding bodies, such as the World Health Organization (WHO), the National Institutes of Health (NIH), Sigma Theta Tau International Honor Society of Nursing (STTI), and the Canadian Institute of Health Research (CIHR) (STTI, 2003). For example, the WHO has acknowledged the importance of international collaboration in nursing by establishing Nursing Collaborating Centers. These centers are mandated to conduct collaborative research of regional or global significance (STTI, 2003).

Despite the growing impetus for ICRTs, our review of scoping literature revealed that there are relatively few resources available to guide and support researchers through the processes of establishing and maintaining ICRTs (Freshwater, Sherwood, \& Drury, 2006). In particular, no articles were found that provided researchers' firsthand accounts of being a member of an ICRT. Having access to such firsthand accounts, can help novice researchers learn more directly about what to expect, as well making them aware of the benefits, challenges, pitfalls, and success strategies of being involved in an ICRT.

This paper builds upon professional and academic experiences and insights of an interdisciplinary team with members from South Africa and Canada. The idea of a manuscript emerged following the 2010 International Nursing Research internship in Jamaica. Dialogue and interaction between the interns, mentors and off site facilitators revealed the need for sharing knowledge and key lessons learned from working within an international collaborative research team. Such informal beginnings are typical, as "most collaborations begin informally and are often the result of informal conversations" (Katz \& Martin, 1997, p.4).

In this paper we highlight key themes that emerged from a phenomenological analysis of our firsthand experiences as researchers within an ICRT. These themes include the benefits, challenges and opportunities of such teams. Our findings are presented here for consideration by others interested in influencing research-based health practice globally.

\section{Literature Review}

\section{Search Strategies}

Key bibliographic databases were searched. Journals and reference lists were hand searched for relevant sources. Working papers, reports from international organizations, and sources retrieved through internet search engines were included to supplement the review. Search terms included a combination of words: international, collaborative, research, and team.

\section{Benefits of ICRTs}

Collaboration and sharing. According to our literature review, there is a general agreement on the benefits of ICRTs. Having multiple researchers, institutions, and countries involved in 
a research project, can reduce duplication and provide more textured understanding and interpretation of results. Such collaboration also presents opportunities for synthesis of expertise and resources, division of expenses, as well as sharing of talents, strengths, and perspectives between developed and developing or newly developed countries (Jone \& Tilden, 1998; Katz \& Martin, 1997; Kim, 2006; Melkers \& Kiopa, 2010). Generally speaking, sharing of talent and skill can result in a better end product (Broome, 1999), whereas multisite research can improve the chances of obtaining a representative sample size within a reasonable timeframe and thereby increasing generalizability of findings-the findings are not constrained to a particular facility or place-specific characteristics. Moreover, multisite ICRTs can also obtain a level of complexity in research that is difficult, if not impossible, to achieve in isolation (Bossert, et al., 2002).

Productivity. Another benefit of working within an ICRT may be improved productivity (Ordóñez-Matamoros, Cozzens, \& Garcia, 2010; Subramanyam, 1983). For example, one study found that co-authoring with partners located in middle-income countries increased team output by nearly 40\% (Ordóñez-Matamoros, et al., 2010). It has also been found that manuscripts with multiple authors have been associated with a higher rate of acceptance for publication (Gordon, 1980), although this may be a debatable claim. Furthermore, collaboration can increase the visibility of the work once it is published by increasing the chance that it might be picked up in a literature search for work produced by any one of the contributing authors (Katz \& Martin, 1997). This increases the likelihood of being cited and the concomitant impact of the work (Katz \& Martin, 1997). Overall, ICRTs can serve to encourage interaction between disciplines, to transfer knowledge and techniques, and disseminate results. In addition, the final output has the potential to be of a higher standard than that of individual research institutes, due to synergistic effects (Boonekamp, et al., 2000).

\section{Challenges of ICRTs}

Although there are many benefits of ICRTs there are also many challenges and pitfalls. The following four sub themes related to challenges and opportunities emerged from the literature and are discussed. The four sub themes include: communication, relationship building, issues of authorship, and planning and coordination.

Communication. In the literature that deals with ICRTs, communication and relationship building are identified as the most critical challenges in establishing and maintaining effective and successful international collaborative research teams (Bossert, et al., 2002; Broome, 1999; Fisher \& Osborne, 2000; STTI, 2003). Effective communication demands attention to and accommodation of differences among countries related to culture, language and translation requirements, time zones, and academic calendars, as well as national, ethnic, or religious holidays (Freshwater, et al., STTI, 2003). Face to face interaction is generally considered a gold standard of communication. Indeed, face-to-face collaboration in a location free from distractions can facilitate immediate brainstorming and sharing of ideas, enhanced conflict management, and "serendipitous research and discovery" (Hampton \& Parker, 2011, p. 901). However, face-to-face collaboration is not always feasible for international teams, especially those in the early phases of team and project development. Telephone or Skype conference calls can serve as good alternatives. Texting meetings through open access internet communication tools, such as Microsoft Network (MSN) or Skype, pose another alternative 
to meeting in person. However, texting does not have the benefits of voice tone or nonverbal communication. Emoticons can contribute to some extent, but these, along with humor, irony, puns, and other strategies should be used with caution in the absence of nonverbal cues, as they could be misunderstood (Bossert, et al., 2002).

In order to facilitate effective communication on all levels, meetings should be chaired by the Principle Investigator (or team leader), have an agenda, and be followed-up promptly with minutes (Bossert, et al., 2002). Meetings should be scheduled regularly, but should not overwhelm team members who, more often than not, have tight schedules with multiple competing time commitments. Regular meetings provide opportunities to establish momentum, ensure that everyone has shared information and understanding, oversee time line progress, give brief progress reports, and make modifications to the original plan, as needed (Abell \& Rutledge, 2009).

Relationship building. The above mentioned basic communication components and practices lay the ground work for the more complex task of relationship building. Fundamental to relationship building in an international collaborative research team, is effective team leadership. Team leaders should be experienced and knowledgeable about the research process and have flexible work responsibilities (Bosset, et al., 2002). An effective leader facilitates agreement about the goals, purpose, roles and responsibilities associated with the project; invites multiple leaders or shared leadership; prevents dominance by any particular member(s); and supports local innovation (Abell \& Rutledge, 2009). Establishing a common purpose and goal(s) right from the beginning is a critical first step for the team leader. The aim must be clear and accepted by each partner (Boonekamp, et al., 2000). Most research endeavors are quite lengthy and a common goal can serve to remind everyone why they are involved and can help maintain focus and productivity (Jones \& Tilden, 1998). To facilitate productivity toward the common goal, all team members should have equal and timely access to data, information, and results pertaining to the work. It stands to reason that all information concerning the research should be kept confidential until the research is published (Fisher \& Osborne, 2000).

In like manner, effective leaders in ICRTs work immediately and continuously to establish trust, respect, and team spirit. This can be a challenge when teams interact by using virtual technology, as trust only develops over time by getting to know one another (Jones \& Tilden, 1998). Therefore, all team members need to be aware of their own motives and underlying assumptions, biases and expectations with regard to writing and working with other researchers. Additionally, they have to be good listeners and recognize that little things indeed matter; that is, respectful engagement, extensions of good will, public acknowledgement, and expressions of gratitude (Abell, \& Rutledge, 2009). In a cohesive team, all members must feel valued for the unique skills and expertise they contribute (Bossert, et al., 2002).

Patience, flexibility and perseverance when working with other researchers are also critical attributes when working as a team. No one should be embarrassed for not being able to fulfill their assigned responsibilities. Competing time demands for individual team members can be pressing and can arise unexpectedly (Abell \& Rutledge, 2009). If it appears that a team member is not sharing his/her load, it is incumbent of the team to discuss the problem and find a satisfactory resolution. For example, it must be determined if a particular team member is still interested in the project and, if need be, pick up that person's work (Broome, 1999). At times the team leader may need to re-instill motivation in individual team members or in the 
team as a whole (Bossert, et al., 2002), as well as set the stage for open sharing and working through any conflict that might arise, so that it can be discussed timely and constructive problem solving can take place (Fisher \& Osborne, 2000).

Issues related to authorship. Besides the above mentioned potential communication deficiencies, ICRTs may bring added complexities to issues of authorship. For the sake of integrity and scientific accountability, authorship should be proactively negotiated right at the beginning of the project (Jones and Tilden, 1998). Although many researchers may be involved, authorship only belongs to those who write the article, and not to those who only make an occasional or minor contribution (Fisher \& Osborne, 2000; Jones and Tilden, 1998; Katz \& Martin, 1997). Authorship should not be granted as a gift or gesture of friendship or courtesy. Instead, honorees can be mentioned in the acknowledgement (Fisher \& Osborne, 2000; Jones and Tilden, 1998). It is also important to establish agreement in the team that each author is responsible for the full body of work, not just the section they write (Jones and Tilden, 1998).

Ordering of authors on the title page is often a challenge, and there are various guidelines but no established rules. The first author is usually the Principle Investigator or team leader (Bosset et al., 2002), while the order of subsequent authors is commonly negotiated by consensus based on the significance of the individual's contribution (Jones and Tilden, 1998). It is, therefore, important for individual authors to keep track of what they have done, whereas journals nowadays more often require a summary of each author's specific contribution towards the final text. For example, the International Committee of Medical Journal Editors (ICMJE) recommends that authorship be based on " 1) substantial contributions to conception and design, acquisition of data, or analysis and interpretation of data; 2) drafting the article or revising it critically for important intellectual content; and 3) final approval of the version to be published" (ICMJE, 2009, para. 3). Journals following the ICMJE guidelines often request that authors declare that they have met all three of these conditions.

Usually co-authors then have the right to propose subsequent publications and assume first authorship (Bosset et al., 2002; Jones \& Tilden, 1998). However, secondary analysis or future papers should be undertaken only after receiving written permission from other collaborators of the primary project (Fisher \& Osborne, 2000). Other team members might be invited to co-author subsequent publications, but they do not necessarily have authorship unless they actually contribute (Jones \& Tilden, 1998). It is important to stress that any dissemination of data, information, or results associated with the work beyond the network should not be done except by agreed-upon means (Fisher \& Osborne, 2000). Finally, the target journal should also be negotiated before the writing process commences, to assure that it is relevant to the various disciplines (Jones \& Tilden, 1998).

Planning and coordination. For an international collaborative research team to be successful the research must be carefully planned and multiple sites must adhere to the plan. The research plan must take into account the differing policies and guidelines at the various sites involved. In addition, each site needs at least one qualified collaborator who, like the PI, has time, flexibility, knowledge, skills, and resources to conduct the research and can assume responsibility for the project at that specific site (Bosset, et al., 2002). These senior, experienced collaborators can work locally with novice collaborators as their mentors and guides. Team members may be recruited through a variety of means, for example existing 
professional relationships, professional meetings and conferences, consultations, or professional groups and organizations (Bosset, et al., 2002).

In addition to researchers, the project may also require the services of project coordinators, statisticians, administrative assistants, or transcriptionists (Bosset, et al., 2002). These are usually paid positions that would have to be factored into the funding plans. Regarding funding and grant applications, the team must negotiate at an early stage who will take the responsibility for obtaining and managing the funding and if the funding will come from more than one source (Bosset, et al., 2002).

Although it may vary from institution to institution, each participating site usually requires approval from their respective Ethics Review Boards to conduct any research, funded or not, that involves human subjects. Letters of support from key decision makers may also be needed from each site (Bosset, et al., 2002).

As mentioned earlier, planning normally begins with initial contact and informal meetings that invite ideas and comments. It is important at this stage to avoid setting up false expectations or promises (Oda, O'Grady, \& Strauss, 1994). As the discussions progress, the aim of the research should become clear and be accepted by each member (Boonekamp, et al., 2000). The team can then advance to collaboratively creating a joint document or terms of reference that outlines the team's purpose, goals, objectives, membership, governance, modes and frequency of communication, as well as authorship guidelines. Terms of reference should be drawn up at the beginning with input from all members. These documents are dynamic and need to be reviewed and revised as necessary (Fisher \& Osborne, 2000).

There is a growing body of literature that outlines benefits and challenges of establishing and maintaining international collaborative research teams. However, no articles were found that provide researchers' firsthand experiences as a member of an international research team. Our article aims to supply a firsthand account of working within an ICRT which can help novice researchers learn more directly about the realities of membership of such a team: what works and what doesn't work, what are the advantages and disadvantages, as well as challenges and opportunities of being involved in an ICRT?

\section{Methodology}

In spite of the substantial body of literature to which we referred at an earlier stage, it seems that there are currently very few research articles available dealing with firsthand experiences of members of ICRTs. To address this gap in the literature, the authors used reflective topical autobiography to capture our experiences as members of a research team. Reflective topical autobiography aims to capture and describe experiences of a person (or persons) to "make the world of lived experience of that person directly accessible to others" (Johnstone, 1999, p. 25). Reflective topical autobiography is influenced by phenomenological approaches that emphasize self-reflection, reflexivity, and emersion in the research experience (Anderson, 2006; Friedman, 1990; Johnstone, 1999; Kimble, 2010). It is not our intention to present an objective, detached "truth" about membership in ICRTs. Instead, by sharing our lived experiences, we hope to render an account that advances shareable understandings of what it is like to participate in an ICRT (Anderson, 2006; Johnstone, 1999; Kimble, 2010).

In order to guide authors in the free writing process, an author reflection guide was used. Consistent with reflective topical autobiography and phenomenological approaches, the guide 
contained broad topics to be covered (Johnstone, 1999; van Manen, 1997). Authors were encouraged to write freely and only on the topics that were relevant and meaningful for them. The first question in the guide, addressed the grand tour: Describe your experience of establishing an international collaborative partnership. Other probes contained topics related to establishing and maintaining team spirit, communication strategies and tools, authorship negotiation, membership recruitment and retention, and ethical considerations.

Four authors from the team participated in the journal reflection process. These team members were from South Africa (van der Walt, Watson, \& Linda) and Canada (Carr). They represented a range of experience and expertise as researchers and as members of ICRTs. Disciplinary backgrounds represented, included nursing, industrial psychology, and sociology. In accordance with van Manen's (1997) thematic analysis, data analysis and data collection occurred concomitantly. Analysis involved several readings by all team members of the authors' written reflections, including their own. As researchers we had the unique challenge of also being research participants. As we began to analyse the data, it soon became obvious that we needed to keep our coding and new reflections separate, as the coding process often stimulated new thinking and reflections on our own experience. To manage this, we created a coding table with three columns. The left column contained the reflection text to be coded, the second column contained the codes, and the third column contained any new reflections that emerged as the coding was being done. New reflections were then subjected to the same analysis process. Coding and reflection was, therefore, an iterative process, that continued until no new ideas emerged.The credibility of the findings was strengthened by the inclusion of the multiple disciplinary perspectives and a variety of experience and expertise in the sample. Initially, data was analyzed separately by four researchers and then discussed until agreement was reached with regards to a shared interpretation (Toma, 2006).

\section{Findings}

\section{Benefits of ICRTs}

Our overall experience with ICRTs has been positive and we have observed and experienced many benefits on personal, professional, and global levels. A major benefit is that we have expanded our international professional networks. This international networking has, in turn, enhanced our global understanding through cooperative learning, resource sharing, and exposure to multiple perspectives and cultural contexts. Van der Walt's reflection summarizes these multiple benefits well:

\section{In the first instance, I met people (other researchers), not only in the field of nursing but also in Public Health, Epidemiology, Sociology, etc. Interacting with researchers outside my specialty broadened my borizon as a person but also as a researcher.}

In terms of cooperative learning and enhanced global understanding, Watson wrote:

\footnotetext{
All of us participating in this [ICRT] project gain more capacity in international collaboration from our interactions, as we have the opportunity to respond, reflect and test ideas with each other in real time.
} 
As members of ICRTs, we have also gained confidence along with an enhanced sense of control and ability to influence. Linda and Van der Walt relate:

Sharing of knowledge and information with international partners helps to increase one's capacity to perform expected duties. This in turn increases one's confidence and willingness to provide the expected services with understanding. (Linda)

\section{Being recognized as a member of an international research team contributed to my confidence as researcher (Van der Walt).}

Beyond our own personal and professional development, we recognize the critical role ICRTs can play in the advancement of knowledge within and across countries, cultures and disciplines. Watson, who is an industrial psychologist, believes that:

From these collective interactions we as a group generate public knowledge, knowledge that we are planning to share with other researchers, research users, individuals, groups, organizations and even the community in general can benefit from this knowledge generated.

Likewise, ICRTs can forge strong and mutually beneficial relationships between developed and developing countries. This relationship can result in positive outcomes for all parties involved in critical areas, such as healthcare delivery. Linda, a nursing scholar from South Africa, remarked:

There is a steady growth of a meaningful relationship between the developed and developing counties. This relationship will help to improve the provision of health related nursing services, for example nursing practice, education, and policy making.

In the analysis of our journal reflections, it was clear that we were unanimous that ICRTs are an important, rewarding and worthwhile pursuit. However, we also agreed that there are challenges that must be addressed, in order for ICRTs to form and function effectively. We summarize our reflections on the major challenges we experienced below.

\section{Challenges of ICRTs}

Perhaps not surprisingly, the most common challenges for ICRTs we identified in our reflections were communication and relationship building. For many ICRTs, like those we have participated in, communication is mostly, if not entirely, virtual. Establishing trusting relationships with colleagues across continents and oceans through use of communication technology alone is challenging to say the least. In our teams, most of us have never met in person. We have relied on communication tools, including teleconferencing, instant messaging, and internet meeting room services (or voice over internet protocol), such as Skype and Elluminate. Of all of these tools, teleconferencing is perhaps the most reliable; however, it is also the most expensive, prohibitively so for ICRTs that are just forming and are not yet funded. Free tools, such as Skype, or licensed tools, such as Elluminate, can provide excellent alternatives to teleconferencing. In addition to being more affordable, internet communication tools allow for simultaneous voice and texting, as well as video conferencing. Linda and Watson shared their experience with these technologies:

Skype and Tele-conference (communication) were the most useful strategies. Skype was the cheapest mode and was used often. At times communication errors and sound technical problems were experienced on Skype. But nevertheless it was the most 
preferred. Tele-conference was also handy; however, it was costly to the coordinator (PI) who had to call and connect every one. Elluminate was tried once and appeared to be very good, as the discussions could be moderated, i.e., control of taking turns (Linda).

We make use of both Skype and Elluminate internet based software to communicate. Skype works really well on small group conferences and one-on-one conversation. Elluminate works best with group conferences, and it's great to block out all the external noise, which is not the case with Skype and is somewhat frustrating at times. We once had a text meeting in Skype which was fun and yet very effective, and we were able to make decisions on important matters. Skype is very useful as it's freely available, it's free and the software, in general, doesn't have too many conflicts with other software. Elluminate, however, is, in my mind, the best platform for international collaboration. It is, however, costly for the hosting institutions, and there are some software conflicts which do not make Elluminate that accessible to all (Watson).

For many of us, there was a significant learning curve in becoming proficient with these communication technologies. In addition, team members often experienced weak or interrupted internet connections and some had limited access to information technology (IT) support. The learning curve combined with unreliable connections created stress at times and interfered with team members' ability to focus and fully participate in meetings:

Initially it was not easy for me to follow on any discussion outside the context of the study topic, simply because I was stressing about a lot of things like online connection, sound, being cut-off, etc. As time went on the problem became better (Linda).

As Linda stated, these problems gradually improved over time, both because we became more technologically proficient and also because the technology, itself, continually improved.

Reliance on virtual meeting tools and spaces also created the challenge of getting to know each other through voice and text alone, as so much of communication is nonverbal. Instead of putting names to faces, we had to learn to put names to voices. This took time. Also tone of voice became a replacement for facial expression and was much more difficult to read, especially when taking into account poor or delayed connections and cultural and language differences. Linda explained this well:

Also as I got to know most of the members and being able to identify their voices the whole experience became better. The sense of hearing has been the leading tool in this context. During discussions over Skype and teleconference tone of the voice would enable one to establish the mood and attitude of each voice.

Watson added that for ICRTs, it would be ideal for relationship building if members had the opportunity to meet in person, even if such meetings were infrequent:

Something that helps to a great extent is personal contact. Working with people whom you have met in person makes any interaction so much easier or rather more natural. If you had the opportunity to spend some time with those working with you on a project, you get to know a bit more about that individual and how to interact with them. So, personal contact would be a great advantage in establishing and maintaining spirit, even if it's just seeing each other once a year or at the startup of the project. 
Other challenges associated with ICRTs we identified in our reflections, included membership recruitment and retention, as well as time limitations and competing commitments. For us, membership recruitment to our ICRTs occurred during an international research internship program. Ideas for ICRT projects were posted and interested interns signed up, if they were interested in participating or at least learning more. From there, other interested individuals who did not attend the internship were recruited by word of mouth by participating team members. Carr shared her experience in recruitment as a project team leader:

Carr, as a Postdoc Fellow working in the International Research Internship, took the lead in presenting the idea for the projects and inviting those interested to learn more and/or join the team. Team membership began with the interns and, for one team, snowballed out to include others from our respective communities, who expressed an interest in participating in the team.

One of the challenges with team member recruitment we encountered initially was keeping the teams to a manageable size. Initial interest was strong and membership quickly grew. The ideal size for an ICRT is entirely dependent on the nature and scope of a particular project. For us, our projects were small in scope, but interest was high and we did not want to turn anyone away. This resulted in some teams having as many as ten or more members, which is arguably too large for smaller scale ICRT projects, such as preparing a manuscript for publication. It can be difficult for that many people to make a significant contribution. What is more, relying on virtual technology alone, combined with significant time zone and scheduling differences across countries and continents made relationship building with more than five or six people very challenging. Over time, membership gradually declined to four regular participating members. This gradual decline in membership may be a natural progression with such a team, and starting with slightly more members than needed may be a good strategy for ensuring there will be enough members to complete the task in the end.

Membership retention was nevertheless an important goal, and we all felt a sense of loss when a member backed out or seemed to lose interest. In our reflections, we considered factors that are critical for the retention of members:

Communication in my mind would be the most important thing to do. If you don't talk to your team members on a continual basis, how will you know that they are considering withdrawing? If you are informed, then you will be able to come up with the relevant retaining strategies. Also, having a clear understanding of the different individuals' goals and expectations of the project. Having collective understanding of the project and the project outcomes. Having clear team roles and responsibilities (Watson).

It is possible that membership retention can be impacted by competing commitments and time limitations. For many members of ICRTs with whom we have worked, involvement in such projects is only a small part of their full time profession where work on the team project competes with other professional and personal commitments. Furthermore, the ability to contribute can vary for individual members throughout the span of a year, and unexpected, competing priorities can manifest, making it difficult for members to stay actively engaged and involved on a continuous basis.

\section{Success Factors and Strategies}

Despite the challenges described above, our experience as members of an ICRT has been very successful and positive overall. In our journaling, we reflected on factors that contributed to 
this success and identified the following four broad themes: personal factors, structural factors, communication and relationship building strategies, and leadership. In sharing these success factors and strategies, it is not our intention to provide readers with prescriptive guidelines on how to set up and maintain ICRTs. Every ICRT is unique and some of these ideas may or may not apply in every case. Instead, we are describing what worked for us, and hope that others may benefit from our experience.

Personal factors. In our experience, we found that personal factors and characteristics of individual team members are critical antecedents to the success of an ICRT. Those we identified as most critical included: personal interest and motivation, realistic expectations, honest and realistic commitment, positive attitude, professionalism, risk taking capacity, resourcefulness, and perseverance. According to Watson, such personal factors are fundamental to the overall success of the research partnership:

On a personal and individual level, interest, commitment, willingness to support, and, most importantly, transparency, I think these four aspects encapsulate all other factors and characteristics needed in an effective research partnership.

Working with multiple team members with competing schedules and personal time commitments can sometimes slow down progress toward completion of projects. Van der Walt wrote about the importance of persevering despite these delays: "I find that everything takes a bit longer, but as long as there is a steady progress, which is one of the sacrifices one makes to reap the benefit of multiple inputs."

The importance of honest and realistic personal commitment to the project was reiterated several times in our reflections. For example, Linda reflected: "[It is important to establish] each member's willingness to participate. Availability of time, although there is no perfect way to check on this, but partners may need to ascertain if they are not having other big responsibilities that may interfere with their participation." In order for individual team members to make a realistic commitment, the scope of the work and expectations must be clear in the early stages: "The scope of the work was decided early on in the project, so that team members had a clear sense of their commitment" (Carr). Having said this, Carr went on to reflect on the importance of personal flexibility in terms of commitment level: "However, team members also seemed open to progressing beyond the original project once it was completed, if the opportunity presented itself to extend what we are doing" (Carr). Personal factors, such as commitment level and capacity to participate, were influenced by broader structural factors in the environment.

Structural factors. Structural factors that most influenced the ability of our teams to succeed as ICRT included: support from the workplace, financial resources, and access to technology and communication tools. Academic institutions are increasingly recognizing the importance of forming international collaborative partnerships in both teaching and research. As members of ICRTs, we have all received encouragement and support from our academic workplaces to pursue these projects. For example, regarding the support she received, Linda wrote: "I was seconded by my Head of School and management team to attend the International Research Internship Programme. Since then I am participating in two international projects (Spiritual Team and International Collaboration Research Partnership)." Our workplaces have also provided in kind support, such as secretarial support, photocopying, library resources, IT support, and time: "My University is very excited and supportive about the international relationships I am forging as a result of these projects. I am given secretarial support and time to devote to this work" (Carr). Watson wrote about the 
importance of ensuring workplace support and other key structural factors, such as access to funding, technology, and communication tools are in place from the start:

On an operational level I think there is a lot more to consider, things like finances, resources, organizational structures the political climate of participating countries, etc. the list goes' on. But for this specific project things to consider are things like available time, permission from your institution/head of department, access to a pc and the internet, other resources like a headset, and something that we didn't consider before the time is permission from IT, as we needed to open our firewall to connect from our office $P C$ 's.

ICRTs with strong structural supports and motivated and capable team members are in an excellent position to succeed. However, we found that equally essential to the long term success of ICRTs are communication and relationship building strategies, as well as strong leadership.

Communication and relationship building strategies. A precursor to establishing strong relationships and team spirit is having effective communication strategies and practices in place. Because we relied on newer internet communication tools, such as Skype and Elluminate, we needed to take time to learn how to optimally use these tools. Electronic user guides were circulated to all team members, and team members who had knowledge and experience in using these communication tools in the past helped to mentor those just learning. Even as team members became proficient in using these technologies, unexpected challenges, such as connection disruptions emerged. Perseverance, creativity, and flexibility among team members proved to be critical in working through these challenges. About this Van der Walt wrote:

We have used a variety of communication strategies, from Skype to Elluminate and telephonic discussions. We have settled for Elluminate as platform; although, from our side the university's firewall was a buge challenge to overcome. We sometimes had to settle for a combination between Elluminate and Skype at the same time. Transoceanic disturbances were also challenging at times but the team members were quite creative in texting instead of talking.

While these tools offer the option of video conferencing, in our experience we found that use of webcams tend to slow down the speed of communication to an intolerable level. To share electronic files and other electronic resources we used Dropbox, which we found quite effective.

During meetings it was important to allow time for participants to speak and for their message to travel to others. Until we got used to this slower rhythm of turn taking, we sometimes spoke at the same time or cut each other off accidentally. Elluminate is set up to better avoid these situations and ensure proper turn taking, by allowing only one participant to speak at a time. Carr reflected on the challenges of turn taking in virtual meetings, being comfortable with silence, and ensuring everyone has the chance to speak and be heard:

Team members are encouraged to voice their thoughts and ideas during meetings, as well as by e-mails. It is important for the chair of the meetings to be comfortable with silence, to give people time to think and respond. Also, there can be connection delays between countries, and if people speak too soon, others might be cut off. Thus, pauses between speakers are important. For me, it took a while to get comfortable with silence. 
Holding regular and frequent meetings was also important for ensuring good communication within the team and for maintaining project momentum. In the initial stages, we met approximately every two weeks. We used these meetings to clarify the purpose of our ICRT, as well as team members' roles and responsibilities. We then met monthly to check in, provide updates, and keep the project on our respective radars. Sometimes we met more frequently, depending on what particular task or deadline we were working on. Watson and Van der Walt reflected on the importance of regular meetings to maintain progress and build relationships among team members:

\title{
Frequent communication and maintaining the momentum is important to keep team members motivated (Van der Walt).
}

\begin{abstract}
Getting back to the "How to establish and maintain team spirit", I think the best thing to do is to make contact as soon as possible and as frequently as possible and make use of all possible resources available for making this contact. This project to me is a great example of this. There are regular meetings, and if there's only two or three members that joined, we continued with the meeting anyway, even if we weren't keeping to the agenda, we used the time to build relationships (Watson).
\end{abstract}

Meeting reminders, meeting agendas, and timely follow-up with clear and detailed minutes that included action items for specific team members were basic but essential practices for ensuring good communication and group progress:

Having a formal agenda and minutes at all the meetings with clear action items facilitates a process whereby all members are actively involved in the discussion and in the decision made for the route ahead (Watson).

Also basic but essential was the drafting of a Terms of Reference (TOR) for the ICRT. In our Terms of Reference we included the following: project title, background and purpose, list of team members (including their name and affiliation), operations and governance, team member roles and responsibilities, and authorship guidelines. The Terms of Reference was a working document that was revised as needed, as Van der Walt explained in her journaling:

Each individual member had to negotiate his/her role in the team and that has to be revised and re-negotiated at later stages as well. . . Authorship depended on the role of each member and eventually the input the various members made in the project and writing of the manuscript. Authorship needed to be renegotiated from time to time and especially towards the end.

Watson reflected on how a Terms of Reference document can be important for avoiding conflict or misunderstandings:

Having a memo of understanding is also a great way of sidestepping possible conflicts, for example developing shared authorship guidelines among the members. . This was one of the first discussions that the team had, as this project was about developing and publishing a manuscript which clearly emphasizes the need for negotiating authorship. The authorship guidelines then formed part of the TOR as it was developed.

In addition to the mechanics of setting up consistent and effective communication strategies, relationship and team spirit building also involved getting to know one another personally and professionally; offering mutual respect, support, and encouragement; celebrating small 
wins; and having fun. To get to know each other better, some of us have connected through social media platforms, such as Facebook and LinkedIn. Watson reflected on the importance of getting to know one another through use of technology, as well as having fun:

Technology really helps in connecting to each other. There's a great number of excellent resources out there that team can use to keep connected. The social network platform that exists always can play a big part as you get to know the members on a more social/personal level too. It's nice to see that your team members have fun too, it's not only work.

When reflecting on factors that contributed to team spirit, van der Walt emphasized the importance of mutual respect and personal and professional support: "What I have learned in the process is how people's inputs are valued and how members will support each other, not only in relationship to the project but also personally." Similarly, Carr and Linda commented:

Although we don't even know what some team members look like, meetings on Skype are fun and full of warmth. This is achieved by encouraging all to talk, respecting each other's ideas and opinions, valuing each other as key group members. Also, emphasizing that we are a team is simple but critical (Carr).

Respect among team members has been the most powerful weapon to keep everybody positive about the progress. Respect on how we respond to each other during meeting's discussions. Understanding each other's unexpected circumstances that probibit participation, whether by absence from meetings, submitting work section, etc. This makes members feel committed to contribute to the team work (Linda).

Van der Walt and Carr also pointed out the importance of celebrating small wins:

Emphasizing small wins is important. Smaller sets of outcomes as set on a Gant chart for example, give members a sense of achievement (Van der Walt).

Keeping the group focused on the goal and encouraging members through recognition of accomplishments and appreciation are also key for maintaining team spirit (Carr).

Relationship building can also be enhanced when team members are aware of and sensitive to the unique historical and cultural context of the countries being represented and how this context can influence team members' participation and perception of ICRTs. For example, Watson shares his reflections on how South Africa's history of international isolation has influence current international research endeavors and relationships:

South Africa's history has definitely had a huge impact on how South African researchers conduct collaborative international research. In the past and in some cases, yes, the South African researcher was left behind, because interacting with their international peers wasn't always as possible as it is currently. However, our national diversity is definitely a great plus, as we interact with individuals from different backgrounds on a daily basis. In some cases, I have felt somewhat patronized by my colleagues in mainstream science countries. The reason for this might be that English isn't all South Africans' first language, and we can't always express ourselves as accurately as we would like. In my mind, when it comes to Social Science research, South Africans were and still are, in some cases, being exploited by paternalistic and colonial funding models which boils over 
in research models that places the South African researchers in the passenger seat when doing research in their own country/context.

Watson's comments reflect the need for ICRT members to not only get to know team members as individuals, but also to understand and respect their unique national and historical context as it relates to research and international relationships. This understanding and respect would facilitate trust building and symmetrical collaboration, in which all team members feel that their relative contributions are of equivalent value and importance.

Practices, such as establishing trust and respect, celebrating small wins, and setting a tone of mutual support and symmetrical collaboration, are rooted in strong leadership, which we found to be a fourth critical requirement for ICRT success.

Leadership. Qualities of leadership that we identified as most important in our experience as members of ICRT included: dedication, flexibility, shared leadership, and project management skills. Linda reflected on the leadership qualities she found most important: "Team Leader (PI) leadership style of being dedicated, flexible, supportive and welcoming attitude was definitely a direct input to the outcome." Van der Walt reflected on the importance of the team leader being a strong role model and setting a tone of shared leadership and decision making:

I do think the team lead is crucial in setting the stage in terms of inspiring a shared vision and enlisting others to join the team. Further, the ability to enable others in fostering the collaboration by strengthening mutual trust and sharing power and information is extremely powerful. I found that strong team leaders model the way in setting the example and keeping to promises makes a big difference in the gel that binds the team.

Watson also wrote about the importance of a shared leadership approach, especially from the inception of a project:

This is a great experience for me, as the project was in a beginning phase when I and the other interns joined the project, so there was a lot of conceptualization that happened toward the overall outcome of the project. Something that really stands out for me about this project, and I'm sure it's generalizable to small projects, is that all the members are involved in all the different aspects, from establishing relationships to operationalizing of the ideas. I'm also involved in some of the technical aspects (I'm sure everybody is) regarding connecting with all the members around the globe.

Watson pointed out that project management skills are also an important and ongoing shared responsibility among the team members:

The meetings initially focused on establishing relationships and gaining insight on the member's prior experience and exposure on the general topic of International Collaboration. The overall goallaim of writing and publishing a manuscript was included in the early decisions and everybody had the opportunity to voice their expectations, concerns, etc. From that point forward, all the members were included in the discussions, and the aim, purpose, goals and desired outcomes were determined by the entire team through democratic decisions. Things did change from time to time with reference to the content and process, but the team managed to stick to the outcome and this has proved a great success. 
For shared leadership to be effective, it is ideal to have a mix of experience and diversity of backgrounds and perspectives on the team. Moreover, a strong leader sets a tone early on that such diversity is valued and essential:
Diversity in the group in terms of culture, nationality, educational background, gender, etc. strengthens the interest, credibility, and scope of our work. This diversity is valued by the whole team. . A combination of novice and more experienced researchers sets up opportunities for professional growth for both mentors and mentees. Resources are exchanged from all countries on an equal level. (Carr)

For team leaders and all group members, establishing and maintaining an ICRT is a challenging task. However, modern technological advances and a growing support for international collaboration initiatives worldwide, makes ICRTs a worthwhile and rewarding pursuit.

\section{Summary and Discussion}

The establishment of global linkages and collaborative relationships among health researchers, decision makers, and practitioners is becoming increasingly common. In fact, establishing international collaborative research teams (ICRTs) is a top priority for major international health care organizations and health research funding bodies, and international collaboration is now viewed as an indicator of research quality (Freshwater et al., 2006; Kim, 2006). The aim of this study was to explore our firsthand experiences as members of ICRTs. In the presentation of our findings, we identified and discussed the benefits, challenges, and strategies for success from our perspective as members of ICRTs.

The findings of our study support and expand on existing literature on this topic. Many of the benefits of ICRTs we identified, including expanded professional networks, enhanced global understanding, resources sharing, higher research productivity, and advancement of knowledge within and across countries, have been reported elsewhere (Broome, 1999; Jones \& Tilden, 1998; Katz \& Martin, 1997; Kim, 2006; Melkers \& Kiopa, 2010). Benefits we identified that were unique to our study included enhanced professional confidence, sense of control, and ability to influence. Such benefits can be critical for building research capacity and advancing knowledge in both developing and developed countries alike.

To reap the benefits, ICRTs must overcome numerous challenges. Congruent with existing literature on this topic (Bossert, et al., 2002; Broome, 1999; Fisher \& Osborne, 2000; STTI, 2003), we found communication and relationship building to be the most important challenges in establishing and maintaining ICRTs. Using tools and technology and relying on voice, texting, e-mail, and emoticons to form trusting, professional relationships over space, time, and often poor connections can be a daunting task for all involved. These factors can, in turn, impact membership recruitment and retention efforts, as our study illustrated. However, our experience also revealed that these challenges can be used not as barriers, but as points from which to move forward. Indeed, our successes were rooted in our challenges.

Success factors that were critical in our experience included personal characteristics of team members, specifically, personal interest and motivation, realistic expectations, honest and realistic commitment, positive attitude, professionalism, risk taking capacity, resourcefulness, and perseverance. The importance of such personal factors cannot be underestimated and is supported by existing literature (Abell \& Rutledge, 2009; Freshwater, et al., 2006; Jarvenpaa, Knoll, \& Leidner, 1998; Sanstad, Stall, Goldtein, Everett, \& Brousseau, 1999). Our study also revealed that motivated individuals, in turn, need structural supports to succeed as 
members of ICRTs. Structural support from workplaces in the form of financial resources, access to technology, communication tools, and encouragement from leadership proved critical for facilitating full engagement of ICRT members.

Just as communication and relationship building were the most important challenges, they too were the most important keys to success. Learning, embracing, and adapting to newer communication tools, such as Skype, Elluminate, and instant messaging, although frustrating at times, were key factors for our success. Unlike previously published literature, we shared firsthand our lessons regarding the use of this technology, including what worked and did not work. In reading our experiences other researchers may be less intimidated by the technology and know that it is normal to fumble and stumble along the way and that over time the proficiency of the user improves, as does the technology.

Communication and relationship building were also dependent on having a clear purpose, goals, expectations and timelines; establishing a terms of reference; holding regular and frequent meetings; setting agendas for meetings; and writing and distributing timely minutes with specific and assigned action items. Consistent with these findings, frequent and regular meetings, as well as consistent membership across meetings have been found to be among the strongest predictors of trust and productivity in collaborative research teams (Hampton and Parker, 2011; Jarvenpaa, Knoll, \& Leidner, 1998). Overall, these project management habits and norms are critical for success of an ICRT and should be established early on (Freshwater, et al., 2006).

Finally, the adoption of a shared leadership model that fosters and supports team spirit, mutual respect, and trust among all members may be the most critical success factor of all. This view is supported elsewhere in the literature (Abell \& Rutledge, 2009; Bossert et al., 2002; Jarvenpaa, Knoll, \& Leidner, 1998; Jones \& Tilden, 1998; Hampton \& Parker, 2011) and certainly describes our own experience. Strong ICRT leaders set a tone of shared leadership; are strong role models; are warm and welcoming; have solid project management skills; and value and embrace the historical, ethnic, cultural, professional, and experiential diversity of all team members (Freshwater, et al., 2006).

Several implications for research and policy emerged from our study. While our research contributes to our firsthand experiences as researchers of ICRTs, more research is needed that explores the experiences of researchers from other parts of the world engaged in various forms of research. Our own work is rooted in smaller scale ICRTs. A study of the experience of researchers engaged in larger international research studies would add to our understanding of how to successfully establish and maintain ICRTs for small to larger scale projects. Also, research studies could be designed to compare the experience of ICRT team members from developed and developing countries and establish what additional supports could be put in place to better facilitate ICRTs in these variant locations. In terms of policy, academic organizations and industries interested in promoting international research and global partnerships, need to ensure that interested employees are encouraged, given time and financial or in kind support, as well as access to technology and communications tools needed to succeed.

In conclusion, ICRTs involve individuals from different parts of the world working together toward achieving shared goals. The "team" in ICRTs is the key in achieving these goals, and it is, therefore, important to know and understand the challenges and success strategies for establishing and maintaining ICRTs. In our experience, however, collaboration is more than just achieving scientific goals-it is about building meaningful relationships with fellow 
researchers from around the world. Indeed, the process can be just as valuable and rewarding, if not more so, than the outcomes.

\section{References}

Abell, N. \& Rutledge, S. E. (2010). Awareness, acceptance and action: Developing mindful collaborations in international HIV/AIDS research service. British Journal of Social Work, 40, 656-675.

Anderson, L. (2006). Analytic autoethnography. Journal of Contemporary Ethnography, 35(4), 373-395.

Boonekamp, G. M. M., Costongs, C., Logghe, K. R., \& van der Venne, M. M. E. J. (2000). International networking: A healthy vehicle for research? European Journal of Public Health, 10(2), 143-147.

Bossert, E. A., Evans, S., Van Cleve, L., \& Savedra, M. C. (2002). Multisite research: A systems approach. Journal of Pediatric Nursing, 17(1), 38-48.

Broome, M. E. (1999). Collaborative research: The art of negotiation. Journal of Child $\xi^{2}$ Family Nursing, 2(1), 1-2.

Fisher, I. \& Osborne, K. (2000). Recognizing and countering the potential barriers to success in international public health collaborations. European Journal of Public Health, 10(3), 220-222.

Freshwater, D., Sherwood, G., \& Drury, V. (2006). International research collaboration: Issues, beneftis and challenges of the global network. Journal of Nursing Research, 11(4), 295-303.

Gordon, M. D. (1980). A critical reassessment of inferred relations between multiple authorship, scientific collaboration, the production of papers and their acceptance for publication. Scientometrics, 2(3), 193-201.

Hampton, S. E. \& Parker, J. N. (2011). Collaboration and productivity in scientific synthesis. BioScience, 61(11), 900-910.

International Committee of Medical Journal Editors (2009). Uniform Requirements for Manuscripts Submitted to Biomedical Journals: Ethical Considerations in the Conduct and Reporting of Research: Authorship and Contributorship. Retrieved from http://www.icmje.org/ethical_1author.html

Jarvenpaa, S. L., Knoll, K., \& Leidner, D. E. (1998). Is anybody out there? Antecedents of trust in global virtual teams. Journal of Management Information Systems, 14 (4), 29-64.

Friedman, N. L. (1990). Autobiographical sociology. The American Sociologist, 21(1), 60-66.

Jones, K. D., \& Tilden, V. P. (1998). Authorship issues in multidisciplinary research teams. American Journal for Nurse Practitioners, 2(5), 18. 
Johnstone, M. J. (1999). Reflective topical autobiography: An underutilized interpretive research method in nursing. Collegian, 6(1), 24-29.

Katz, J. S. \& Martin B. R. (1997). What is research collaboration? Research Policy, 26, 1-18.

Kim, K. W. (2006). Measuring international research collaboration of peripheral countries: Taking the context into consideration. Scientometrics, 66(2), 231-240.

Kimble, P. J. (2010). Autoethnographic journey to discover the heart and art of my nursing practice. An Unpublished Masters Thesis. Victoria University of Wellington, New Zealand

Melkers, J. \& Kiopa, (2010). The social capital of global ties in science: The added value of international collaboration. Review of Policy Research, 27(4), 389-414.

Oda, D. S., O'Grady, R., \& Strauss, J. A. (1994). Collaboration in investigator initiated public health nursing research: University and agency considerations. Public Health Nursing, 11(5), 285-290.

Ordóñez-Matamoros, G. H., Cozzens, S. E. \& Garcia,M. (2010). International CoAuthorship and Research Team Performance in Colombia. Review of Policy Research, 27(4), 415-431.

Sanstad, K. H., Stall, R., Goldstein, E., Everett, W., \& Brousseau, R. (1999). Collaborative community research consortium: A model for HIV prevention. Health Education and Behavior, 26, 171-184.

Subramanyam, K (1983). Bibliometric studies of research collaboration: A review. Journal of Information Science, 6, 33-38.

Sigma Theta Tau International. (2003). Sigma Theta Tau International guidelines for international collaborative research. Retrieved from http://www.nursingsociety.org/Research/Pages/guidelines_ICR.aspx

Toma, J. D. (2006). Approaching rigor in applied qualitative research. In F. Conrad \& R. C. Serlin (Eds.) The Sage handbook for research in education: Engaging ideas and enriching inquiry (pp. 405-423). Thousand Oaks, CA: Sage.

Van Manen, M. (1997). Hermeneutic phenomenological reflection. In M. van Manen (Ed.), Researching lived experience (2nd ed., pp. 77-109). London, Ontario, Canada: Althouse Press. 